\title{
MILLING EFFICIENCY ASPECTS DURING MACHINING OF 7075 ALUMINIUM ALLOY WITH REFERENCE TO THE SURFACE GEOMETRICAL STRUCTURE
}

\author{
J. Musial $^{*}$, R. Polasik ${ }^{* *}$, T. Kałaczyński ${ }^{* * *}$, M. Szczutkowski ${ }^{\dagger}$, M. Lukasiewicz $^{\ddagger}$
}

\begin{abstract}
The original results of the experiment related to the comparison of machining efficiency and surface roughness with the use of 3 different milling tools (indexable insert tools) were presented - two of them (tools) were dedicated or recommended to aluminum alloy machining (in this case 7075) and one was a universal head. All tools had different diameters.
\end{abstract}

Keywords: milling, surface roughness, material removal rate, 7075 alloy

\section{Introduction}

One of the most important aspects of cutting (milling), especially high-efficiency machining on CNC machining centers, is the right choice of tool and cutting parameters. These parameters directly affect (alongside the machine tool, workpiece holder or toolholder) the results of machining - process efficiency, surface roughness and other (Polasik et al., 2017, Leppert et al., 2016, Grządziela et al., 2015, Polasik et al., 2017, Łukasiewicz at al., 2014). These parameters also directly determine other parameters - such as power demand or cutting forces that may have significant limitations in the process.

\section{Methods}

Aluminium alloy 7075 has been selected as a machining material. It is characterized by very good machinability and is commonly used to blow mould parts and stamping dies. It is also used in the construction of load-bearing elements of bridges, trucks, trailers, semitrailers of buses, ships, cranes and railway wagons. It is also used for tanks, mining equipment, hydraulic systems and shipbuilding. The cutting tools were identified and marked. The type of the tools was taken into account during the selection as well as their geometry and number of applied blades. Selected inserts were intended for machining of light alloys. Before processing, all inserts were replaced with new ones.

Marking of tools:

G52: LMT FMZ 90 IK, cutting insert: VGCT220530-ALM, LC610T,

G63: LMT FMU 90 IK, cutting insert: ADHX 110305 ER1196-82, LC610T,

G80: PAFANA R646.22-080, cutting insert: SEHT 1204 AFFN, HU7815.

\footnotetext{
* Assoc. Prof. Janusz Musiał, PhD.: Faculty of Mechanical Engineering, University of Science and Technology, Al. Prof. S. Kaliskiego 7, 85-796 Bydgoszcz, PL, janusz.musial@utp.edu.pl

** PhD Robert Polasik: Faculty of Mechanical Engineering, University of Science and Technology, Al. Prof. S. Kaliskiego 7, 85796 Bydgoszcz, PL, robert.polasik@utp.edu.pl

*** PhD Tomasz Kałaczyński: Faculty of Mechanical Engineering, University of Science and Technology, Al. Prof. S. Kaliskiego 7, 85-796 Bydgoszcz, PL, tomasz.kalaczynski@utp.edu.pl

$\dagger \quad$ PhD Marek Szczutkowski: Faculty of Mechanical Engineering, University of Science and Technology, Al. Prof. S. Kaliskiego 7, 85-796 Bydgoszcz, PL, marek.szczutkowski@utp.edu.pl

‡ PhD Marcin Łukasiewicz: Faculty of Mechanical Engineering, University of Science and Technology, Al. Prof. S. Kaliskiego 7, 85-796 Bydgoszcz, PL, marcin.lukasiewicz@utp.edu.pl
} 
Rectangular specimens with the actual size $60 / 40 / 45 \mathrm{~mm}$ were made in order to carry out the experiment. Samples were prepared with the usage of the testing stand - CNC MIKRON VCE 1600 milling center.

The test plan applied was static and determined. Tools and blade feeds were used as variables (Tab. 1). Constants are cutting speed $\mathrm{v}_{\mathrm{c}}$, cutting depth $\mathrm{a}_{\mathrm{p}}$, cutting width ae, and workpiece. Three samples were machined for the each treatment parameter (3 repetitions were done). Each of the treated surfaces was measured 3 times for each individual measurement (the total number of roughness measurements was 9).

Tab. 1: Parameters of tools applied in tests.

\begin{tabular}{cccc} 
Tool type & G 52 & G 63 & G 80 \\
\hline max. width of cut, mm & 52 & 63 & 80 \\
\hline tensioning spindle size, mm $^{20}$ & 20 & 60 \\
\hline number of teeth & 3 & 5 & 6 \\
\hline entering angle, $^{\circ}$ & 90 & 90 & 45 \\
\hline rake angle & 25 & 16 & 15 \\
\hline $\mathrm{a}_{\mathrm{p}}$ max & 15 & 16,5 & 6 \\
\hline
\end{tabular}

Single-pass milling tests were conducted in the axis of the specimen applying the following machining parameters: feed per tooth $\mathrm{f}_{\mathrm{z}}=0.1 ; 0.2 ; 0.3 \mathrm{~mm}$, cutting speed $\mathrm{v}_{\mathrm{c}}=350 \mathrm{~m} / \mathrm{min}$, cutting depth $\mathrm{a}_{\mathrm{p}}=0.5 \mathrm{~mm}$, working engagement $a_{e}=40 \mathrm{~mm}$.

During machining, the cutting zone was cooled and lubricated with the Statoil ToolWay ST 7\% aqueous semi-synthetic oil emulsion.

Measurements of the geometrical structure of the surface of the machined samples necessary to determine the actual contact length were made with a first class accuracy profilographometer according to DIN 4772 - Hommelwrke Hommel T2000 Tester with a TKL 300/17 measuring tip to which the Hommel Printer P 2000 was connected. Measured values, $\mu$ m: Rt, Rmax, Rz-d, Ra.

\section{Analysis of test results}

The obtained results of measurements of the geometrical structure of the surface were analysed. The influence of the type of the tool used was analysed as well as and the feed rate applied to the values of the individual roughness parameters - in both the obtained mean values as well as the extreme ones. They were analysed with the use of the Statistica software package. The results of the analyses were presented in the form of graphs (Fig.1). For the approximation of the graphs, a function of a negative exponent was used, taking into account the weights of the distance between the individual measured values (important due to significant dispersions at some points). The presented charts are used to visualize the changes in the values of particular roughness parameters due to the lack of physical continuity of changes for the tools used.

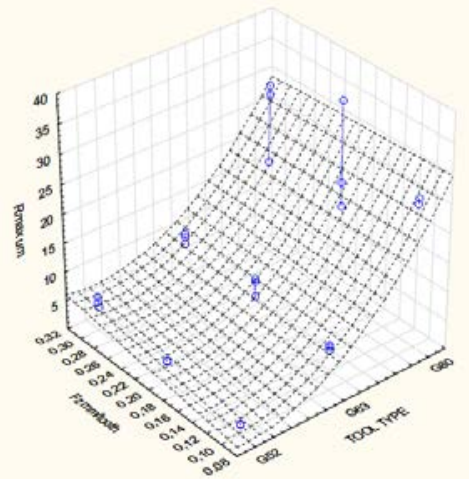

Fig. 1: A graph of changes in the Rmax ( $\mu \mathrm{m})$ value depending on the tool used (TOOL TYPE) and feed rate (Fz, $\mathrm{mm} /$ tooth); indicated in the form of raw data points.

The analysis showed that, with increasing the value of feed on the blade, higher values of roughness parameters were obtained. The surface treated with the G80 tool was characterized by very high dispersion values of individual roughness parameters what indicates the unfavourable conditions of the 
chip formation. At the surface of the tool plates G80 after work there was observed the occurrence of the rise which additionally influences the change of material separation conditions. In case of using the G80 tool, a slight sensitivity of changes in roughness parameters was observed when changing the feed rate setting what was a consequence of the obtainment of the high dispersion.

Volume unitary Specific Removal Rate (SRR), independent of machining (geometric) constraints, was determined from the formula (1):

$$
Q=\frac{a_{p} * a_{e} * v_{f}}{1000}, \mathrm{~cm}^{3} / \min ,(1)
$$

for: $a_{\mathrm{e}}=1 \mathrm{~mm}, \mathrm{a}_{\mathrm{p}}=1 \mathrm{~mm}, \mathrm{v}_{\mathrm{f}}$ resulting from the experimental plan while $\mathrm{v}_{\mathrm{f}}$ was determined from the formula (2):

where:

$$
v_{f}=f_{z} * n * z_{c}, \mathrm{~mm} / \mathrm{min},(2)
$$

$\mathrm{v}_{\mathrm{f}}-$ table feed, $\mathrm{mm} / \mathrm{min}, \mathrm{n}-$ spindle speed, $1 / \mathrm{min}, \mathrm{z}_{\mathrm{c}}-$ number of active teeth.

Spindle speed resulted from the assumed, in the experimental plan, cutting speed $\mathrm{v}_{\mathrm{c}}$ and it was determined from the dependency (3):

$$
n=\frac{1000 * v_{c}}{\pi * D_{\text {cap }}}, 1 / \mathrm{min},(3)
$$

where: $\mathrm{D}_{\text {cap }}$ - cutting diameter at cutting depth $\mathrm{a}_{\mathrm{p}}$, $\mathrm{mm}$.

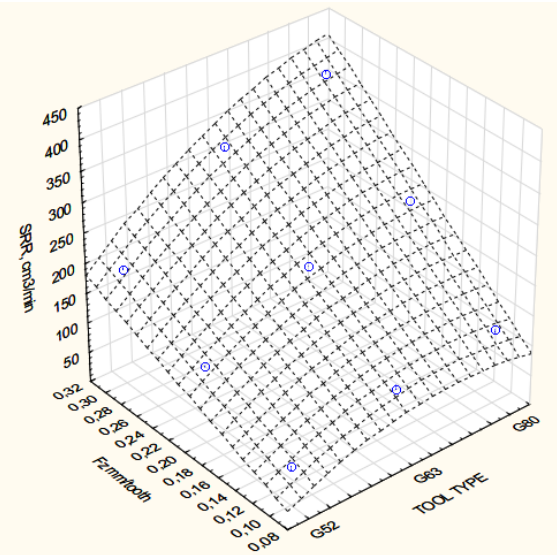

Fig. 2: Visualization of Specific Removal Rate changes (SRR, $\mathrm{cm}^{3} / \mathrm{min}$ ), due to the tool applied (TOOL TYPE) and feed rate ( $\mathrm{Fz}, \mathrm{mm} /$ tooth)

Values of theoretical maximum cutting performance determined from the dependency (1), for $\mathrm{a}_{\mathrm{e}}=$ working engagement, $a_{p}=$ max. are presented in the form of graph in Fig. 3.

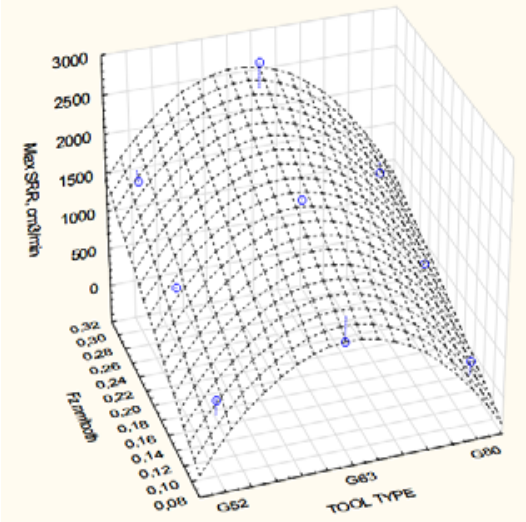

Fig. 3: Visualization of Maximum Specific Removal Rate changes (MaxSRR, $\mathrm{cm}^{3} / \mathrm{min}$ ), due to the tool applied (TOOL TYPE) and feed rate (Fz, $\mathrm{mm} /$ tooth)

Power demand analysis was also carried out during machining with the maximum possible cut-off of the cross-sectional area, for the values of the feeds assumed in the test plan. Theoretical, maximum, power demand was determined from the formula (4):

$$
P_{c}=\frac{a_{e^{*} a_{p} * v_{f} * k_{c}}}{60 * 10^{6}}, k W,(4)
$$


where: $\mathrm{k}_{\mathrm{c}}$ - specific cutting force $\mathrm{N} / \mathrm{mm}^{2}$; for 7075 alloy is $700 \mathrm{~N} / \mathrm{mm}^{2}$. The $\mathrm{K}_{\mathrm{r}}$ angle was taken into account determining the cross sectional area of cut. Calculation results were presented in the form of the graph in Fig. 4.

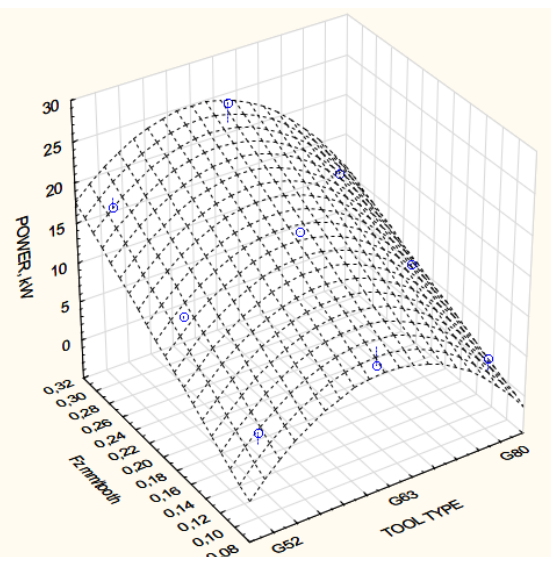

Fig. 4: Visualization of power demand (POWER, $k W$ ) - with reference to the applied tool (TOOL TYPE) as well as feed per tooth, (Fz, mm/tooth)

The analysis showed that the highest removal rate would be achieved using the G63 tool, both in terms of the specific removal rate as well as the maximum removal rate resulting from the geometric features used in the tool tests. The G52 and G80 tools were characterized by lower performance values that obtained similar values for both tools. A similar nature of the changes was observed by analysing the impact of the tool used and the feed for power demand.

\section{Conclusions}

The smallest values of roughness parameters were obtained by machining the 7075 alloy using the G52 tool with dedicated geometry of the tool body and cutting edges. In addition, the polished surface of the plates made in uncoated carbide prevented the formation of the growth what consequently resulted in very high reproducibility of the obtained roughness parameters.

The highest values of the roughness parameters were obtained by machining the 7075 alloy using the G80 tool with universal tool geometry and the universal geometry of cutting edges - designed for the treatment of non-ferrous alloys. Moreover, the rake face of the inserts was not resistant to the formation of the build up, which resulted in the small reproducibility of the obtained roughness parameters (large disportion)

The largest analytically determined volumetric removal rate was determined for the G63 tool. At the same time this tool is characterized by the greatest power demand. The surface geometry obtained with the use of the universal tool equipped with aluminium alloy treatment plates was marginally worse than the tool with a strictly dedicated design for the treatment of aluminium alloys. The choice of a dedicated tool may be caused by the necessity of obtaining very smooth surfaces or occurrence of limitations related to the available motor power of the spindle drive.

\section{References}

Grządziela A., Musiał J., Muślewski Ł., Pająk M. (2015) A method for identification of non-coaxiality in engine shaft lines of a selected type of naval ships. Polish Maritime Research Vol. 22 No. 1(85), pp. 65-71.

Leppert T., Paczkowski T, Polasik R. (2016) The influence of cooling conditions on surface roughness after milling Mechanik, 89, 10, 1420-1421(in Polish).

Łukasiewicz M., Kałaczyński T., Musiał J., Shalapko J. (2014) Diagnostics of buggy vehicle transmission gearbox technical state based on modal vibrations. Journal of Vibroengineering Vol. 16, Issue 6, pp. 3137-3145.

Polasik R., Kałaczyński T., Musiał J., Szczutkowski M, Siegert M. (2017) Grinding forces during machining, using grinding wheels with different characteristics. Actual problems of modern sience, Khmelnytsky - Ukraine : Khmelnitsky National University, (in Polish).

Polasik R., Musiał J., Kałaczyński T., Kochański R. (2017) Mass index of geometric structure change of the surface of objects made of aluminum alloy 7075 after machining. Inżynieria i Aparatura Chemiczna, IZACAX56, 217218, (in Polish). 